Fetal Diagnosis and Therapy

\title{
Clinical Perspective of Cell-Free DNA Testing for Fetal Aneuploidies
}

\author{
Eduard Gratacós ${ }^{a} \quad$ Kypros Nicolaides ${ }^{b}$ \\ a Barcelona Center for Maternal-Fetal and Neonatal Medicine (BCNatal), Hospital Clínic and Hospital Sant Joan de \\ Deu, IDIBAPS, University of Barcelona, and Centre for Biomedical Research on Rare Diseases (CIBER-ER), Barcelona, \\ Spain; ${ }^{b}$ Harris Birthright Research Centre for Fetal Medicine, King's College Hospital, London, UK
}

\section{Key Words}

Cell-free DNA testing · Fetal aneuploidies · Trisomies 21, 18 and 13

\begin{abstract}
Cell-free DNA testing in maternal blood provides the most effective method of screening for trisomy 21 , with a reported detection rate of $99 \%$ and a false positive rate of less than $0.1 \%$. After many years of research, this method is now commercially available and is carried out in an increasing number of patients, and there is an expanding number of conditions that can be screened for. However, the application of these methods in clinical practice requires a careful analysis. Current first-trimester screening strategies are based on a complex combination of tests, aiming at detecting fetal defects and predicting the risk of main pregnancy complications. It is therefore necessary to define the optimal way of combining cell-free DNA testing with current first-trimester screening methods. In this concise review we describe the basis of cell-free DNA testing and discuss the potential approaches for its implementation in combination with current tests in the first trimester.

ㄷ) 2014 S. Karger AG, Basel
\end{abstract}

\section{Introduction}

Fetal chromosomal abnormalities, particularly numerical anomalies (aneuploidies) such as Down syndrome and other trisomies, are common and their detection has been one of the main goals of fetal medicine. Prenatal diagnosis of fetal aneuploidies requires invasive procedures but these are risk-associated and expensive; consequently, strategies have focused on the development of effective methods of screening to define the group in need for such invasive testing.

In the last 25 years, screening for aneuploidies has evolved from simple approaches based on maternal age, to current first-trimester composite algorithms that combine maternal age with epiphenomena associated with fetal aneuploidy, such as nuchal translucency and the levels of pregnancy-related proteins in maternal blood, mainly pregnancy-associated plasma protein A and human chorionic gonadotrophin. These screening strategies have been shown to achieve detection rates for Down syndrome of $90 \%$ with false positive rates of $5 \%$ [1].

The analysis of cell-free DNA (cfDNA) in maternal plasma has created a new reality in the search for effective methods of screening of fetal genetic defects. The concept became possible after the discovery in 1997 that a high proportion of cfDNA fragments (around $150 \mathrm{~kb}$ each) in

\section{KARGER}

E-Mail karger@karger.com www.karger.com/fdt
(C) 2014 S. Karger AG, Basel

$1015-3837 / 14 / 0353-0151 \$ 39.50 / 0$
Eduard Gratacós

Barcelona Center for Maternal-Fetal and Neonatal Medicine (BCNatal) Hospital Clínic and Hospital Sant Joan de Deu, IDIBAPS, University of Barcelona ES-08028 Barcelona (Spain)

E-Mail gratacos@ clinic.ub.es 
maternal plasma are of fetal origin [2]. The first clinical application of this discovery is in the non-invasive diagnosis of the fetal Rh blood type [3,4]. While the goal of assessing fetal aneuploidies in maternal blood was far more challenging, intensive research over recent years has led to the development of several solutions which are now commercially available. A growing number of studies have provided evidence that cfDNA testing outperforms by far any other screening strategy described to date [5] and this is also true for low-risk pregnancies [6, 7]. A recent meta-analysis of clinical validation or implementation studies of maternal blood cfDNA analysis in screening for aneuploidies has reported that the weighted pooled detection and false positive rates were, respectively, 99.0 and $0.08 \%$ for trisomy $21,96.8$ and $0.15 \%$ for trisomy 18 , and 92.1 and $0.20 \%$ for trisomy 13 [5].

It could be argued that since cfDNA testing is highly effective in screening for trisomies and the test involves the simple taking of a maternal blood sample, the stage is set for the widespread introduction of this method in routine clinical practice. However, such widespread use is limited by the relatively high cost of the test and the lack of consensus about the optimal way for its introduction. For example, cfDNA analysis could miss a few of chromosomal abnormalities other than the major trisomies that are currently detected by conventional screening and invasive testing [8]. Likewise, cfDNA testing does not substitute or preclude the need for first-trimester screening for fetal defects and other major complications of pregnancy [9-11]. Thus, the optimal way of incorporating these news methods in combination with existing tests is still undefined and scientific societies have released position statements cautioning about widespread use of cfDNA testing in low-risk populations [12-14]. However, the uptake of cfDNA testing is skyrocketing and healthcare providers face increasing demands from patients for providing advice and offering the test.

In this paper we describe the main commercially available methods of analysing cfDNA in maternal blood for fetal aneuploidies and provide suggestions for the introduction of this method in fetal medicine practice.

\section{Overview of Available Methods for cfDNA Testing in Maternal Blood}

Chromosomes are formed by DNA and proteins, primarily histones, which keep the DNA compacted in the form of chromatin. DNA molecules consist in two strands coiled around each other. The two DNA strands are made up of a sequence of four possible nucleotides, differentiated by the type of nitrogenous base (adenosine, guanine, thymidine and cytosine). Each strand is coupled with the other by base pairs (A-T or C-G). The sequence of base pairs is unique for each chromosome and its molecular units, the genes.

An important challenge in the analysis of fetal cfDNA in maternal plasma is that it is mixed with a much larger amount of maternal cfDNA. Theoretically, the whole fetal genome could be analysed, but this remains a major challenge [15]. For this reason, the first generation of commercial tests has focused on the detection of trisomies 21, 18 and 13, and sex chromosome aneuploidies. The analysis of single gene disorders, such as cystic fibrosis, is still not possible, but a very recent development has been the ability to detect selected microdeletion/microduplication syndromes.

Three methods for the analysis of cfDNA in maternal blood have so far been used in clinical studies: massively parallel shotgun sequencing (MPSS) [16-19], chromosome-selective sequence analysis (CSS) [20-22], and single nucleotide polymorphism (SNP) only based analysis [23-25].

\section{MPSS and CSS}

In MPSS and CSS, many millions of cfDNA fragments in maternal plasma (both maternal and fetal) are sequenced. Since the sequence of the whole human genome is known, the origin of each fragment can be established and the amount of DNA fragments originating from any given chromosome can be quantified. In trisomic pregnancies the number of molecules derived from the extra chromosome, as a proportion of all sequenced molecules, is higher than in diploid pregnancies. The ability to detect this difference necessitates that firstly, the number of counts for every chromosome is high, and secondly, the minimum amount of cfDNA in maternal blood that is fetal in origin (fetal fraction) should be $3-4 \%$.

In MPSS, molecules from all chromosomes are examined with the potential to identify all aneuploidies. However, since chromosome 21 represents only approximately $1.5 \%$ of the human genome, it is necessary to sequence many millions of molecules from the complete genome to ensure sufficient chromosome 21 counts for differentiation between trisomy 21 and euploid pregnancies. This method provides high-performance screening for trisomies 21,18 and 13 and sex chromosome aneuploidies with a low $(<2 \%)$ failure 
rate to provide results. Additionally, some companies using MPSS have recently launched an extended test to include some microdeletion/microduplication syndromes, such as the relatively common 22q (DiGeorge syndrome).

In CSS, selective assays are directed against specific regions on chromosomes $21,18,13, \mathrm{X}$ and $\mathrm{Y}$ before sequence analysis. CSS also evaluates polymorphisms on other chromosomes to estimate the fetal fraction. The advantage of this approach is reduced cost because the number of regions that need to be sequenced is substantially lower than with whole genome sequencing in the detection of the specific aneuploidies of interest and the simultaneous measurement of fetal fraction in the same assay. The disadvantage is that the failure rate to provide results may be higher $(2-4 \%)$ than with MPSS.

\section{SNP-Based Testing}

SNPs are variations in DNA that help distinguishing among individuals. SNP represents a difference in a single nucleotide (a base) within a given DNA sequence which is otherwise identical among subjects. For instance, a SNP would look like this: subject 1:...AGATAGC...; subject 2: ...AGATAGC.... Known SNPs amount to thousands and can be strongly associated with individual traits, including for instance height or differences in the response to therapies [26].

SNP-based testing for fetal DNA assessment uses the principle that the fetus has different SNPs than the mother $[23,27]$. Both maternal plasma cfDNA, which contains a mixture of maternal and fetal DNA, and buffy coat DNA, which is maternal in origin, are examined. Using multiplex PCR, a variation of conventional PCR, about 20,000 polymorphic loci on chromosomes 21,18 , $13, \mathrm{X}$, and $\mathrm{Y}$ are simultaneously quantified. The method detects if there are differences in the maternal and fetal SNPs belonging to a given chromosome and uses complex mathematical calculations to estimate if the distribution of the fetal with respect to the maternal SNPs is consistent with monosomy, disomy or trisomy. The test also requires that the minimum fetal fraction is $3-4 \%$ and the reported performance for trisomies 21, 18 and 13 is similar to that of MPSS and CSS, but the reported rate of non-informative tests is $3-5 \%$. The SNP-based method can identify abnormalities, such as triploidy [25], that escape detection using other methods. The company using the SNP-based method has recently launched an extended test to include some microdeletion/microduplication syndromes.

Techniques, Results and Integration with Existing Screening Strategies

\section{Practical Aspects on the Use of cfDNA Testing in Maternal Blood}

\section{Eligible Pregnancies}

Extensive studies have demonstrated the high performance of cfDNA testing as a screening test in singleton pregnancies for trisomies 21 and 18, and less so for trisomy 13 and sex chromosome aneuploidies [5]. A few studies on a small number of patients have shown that the performance cfDNA testing is high also in twin pregnancies [28-30].

\section{Gestational Age at Testing}

The test can be carried out from 10 weeks' gestation onwards. At lower gestations the fetal fraction is too low for reliable results.

\section{Transportation and Analysis of Samples}

At present most samples are analysed in a few private laboratories in the USA and China, but it is anticipated that within the next couple of years several laboratories will be set up in many other countries.

\section{Cost of the Test}

The cost of cfDNA testing varies between EUR 500 and 2,500 and is considerably higher than that of the currently available screening methods. Widespread uptake of the test will inevitably lead to a reduction of cost.

\section{Time Interval to Results}

The average interval between sampling and providing results is about 10 calendar days. In more than $95 \%$ of cases a result is available within 14 days, but in $2 \%$ of cases a result may not be available in less than 3-4 weeks, especially in those requiring repeat sampling.

\section{Presentation of Results}

cfDNA analysis of maternal blood is a screening test and not a diagnostic test. Consequently, the results are given in terms of risk, with the majority of companies reporting results for each chromosome as low risk (usually $<1$ in 10,000$)$ or high risk ( $>99 \%)$.

\section{No Result}

In $1-5 \%$ of singleton pregnancies no result is given after first sampling, either because of problems with sample collection and transportation to the laboratory, low fetal fraction or assay failure [5]. Failure to obtain a result is more common in overweight and obese patients $[31,32]$. On repeat sampling, a result is obtained in 
about 100,50 and $75 \%$ of cases in which on first sampling there was a sample collection and transportation problem, low fetal fraction or assay failure, respectively [33].

\section{Implications of a High-Risk Result}

The likelihood that a fetus is affected if cfDNA testing gives a high-risk result is about 1,240, 650 and 460 for trisomies 21, 18 and 13, respectively [5]. Consequently, the chances that a fetus from a given pregnancy is truly affected depend on the prior risk for that pregnancy. For example, if prior screening by the combined test had shown that the risk for trisomy 21 was 1 in 12,400 and cfDNA testing gives a high-risk result, the chance that the fetus is affected is 1 in 10; in contrast, if the risk from the combined test was 1 in 2,480 the chance that the fetus is affected is 1 in 2 . It is advisable that in all cases of a high-risk result from cfDNA testing the patients are offered invasive testing for definitive diagnosis.

\section{Implications of a Low-Risk Result}

The negative likelihood when cfDNA testing gives a low-risk result is about 1,000, 31 and 13 for trisomies 21 , 18 and 13, respectively [5]. Consequently, the chances that a fetus from a given pregnancy is truly unaffected depend on the prior risk for that pregnancy. For example, if prior screening by the combined test had shown that the risk for trisomy 21 was 1 in 500 and cfDNA testing gives a low-risk result, the chance that the fetus is affected is 1 in 500,000; in contrast, if the risk for trisomy 13 from the combined test was 1 in 2 and cfDNA testing gives a low-risk result, the chance that the fetus is affected is 1 in 26.

\section{Clinical Implementation of cfDNA Testing in Maternal Blood}

\section{Private Patients}

At present, cfDNA testing is primarily funded by the patients themselves but in some cases they are reimbursed by insurance companies. In most developed and developing countries there is widespread screening for trisomy 21 and patients who can afford to pay choose this over other tests because of its better performance. The best approach to implement primary screening for trisomies by cfDNA testing is to take the maternal blood at 10 weeks' gestation [33]. The results of the test would then be available at the time of the scheduled first-trimester ultrasound examination, which is ideally per- formed at 12 weeks. Such an approach retains the advantages of firstly, diagnosis of the major trisomies within the first trimester, and secondly, early diagnosis of major fetal defects and assessment of risk for pregnancy complications.

A second group of private patients request cfDNA testing as an alternative to invasive testing if first-line screening by an alternative method identifies them as being at high risk for a specific trisomy. There is also an increasingly expanding third group of patients who request cfDNA testing for further reassurance because first-line screening by an alternative method identifies them as being at intermediate risk for a specific trisomy.

\section{Government- or Insurance-Funded Healthcare}

\section{Systems}

There are essentially two options in the clinical implementation of cfDNA testing and the choice will ultimately depend on the cost of the test by comparison to that of other methods of screening. The first option is to offer cfDNA testing routinely to the whole population. The estimated performance of such an approach is the detection of about $99 \%$ of fetuses with trisomy 21 and $95 \%$ with trisomies 13 and 18 at an overall invasive testing rate of $1 \%$ [34]. In this strategy it would be best to carry out cfDNA testing at 10 weeks' gestation, as explained above for private patients.

The second option is to offer cfDNA testing contingent on the results of first-line screening by another method, preferably the first-trimester combined test. In the latter option, cfDNA testing could be offered to the high-risk group as an alternative to invasive testing or to the intermediate-risk group as a method of selecting the small subgroup that could benefit from invasive testing. The exact risk cut-offs that define the high- and intermediate-risk groups will depend on the cost of cfDNA testing and therefore the proportion of the population that can be offered this test.

In one contingent model it was proposed that combined screening is used to divide the population into very high-risk $(\geq 1: 10)$, intermediate-risk $(1: 11-1: 2,500)$ and low-risk $(<1: 2,500)[5]$. In the very high-risk group invasive testing is carried out in all cases and in the intermediate-risk group cfDNA testing is carried out followed by invasive testing for those with a screen-positive result. Such policy would necessitate cfDNA testing in about $25 \%$ of the population and would detect about $98 \%$ of fetuses with trisomies 21,18 and 13 , at an overall invasive testing rate of $0.8 \%[5]$. 


\section{References}

1 Wright D, Syngelaki A, Bradburi I, Akolekar R, Nicolaides KH: First-trimester screening for trisomies 21, 18 and 13 by ultrasound and biochemical testing. Fetal Diagn Ther 2014; 35:118-126.

-2 Lo YM, Corbetta N, Chamberlain PF, Rai V, Sargent IL, Redman CW, Wainscoat JS: Presence of fetal DNA in maternal plasma and serum. Lancet 1997;350:485-487.

- 3 Lo YM, Hjelm NM, Fidler C, Sargent IL, Murphy MF, Chamberlain PF, Poon PM, Redman CW, Wainscoat JS: Prenatal diagnosis of fetal $\mathrm{RhD}$ status by molecular analysis of maternal plasma. N Engl J Med 1998;339:1734-1738.

-4 Akolekar R, Finning K, Kuppusamy R, Daniels G, Nicolaides KH: Fetal RHD genotyping in maternal plasma at 11-13 weeks of gestation. Fetal Diagn Ther 2011;29:301-306.

-5 Gil MM, Akolekar R, Quezada MS, Bregant B, Nicolaides KH: Analysis of cell-free DNA in maternal blood in screening for aneuploidies: meta-analysis. Fetal Diagn Ther 2014;35:156173.

6 Nicolaides KH, Syngelaki A, Ashoor G, Birdir C, Touzet G: Noninvasive prenatal testing for fetal trisomies in a routinely screened firsttrimester population. Am J Obstet Gynecol 2012;207:374.e1-e6.

7 Bianchi DW, Parker RL, Wentworth J, Madankumar R, Saffer C, Das AF, Craig JA, Chudova DI, Devers PL, Jones KW, Oliver K, Rava RP, Sehnert AJ; CARE Study Group: DNA sequencing versus standard prenatal aneuploidy screening. N Engl J Med 2014;370: 799-808.

-8 Syngelaki A, Pergament E, Homfray T, Akolekar R, Nicolaides KH: Replacing the combined test by cell-free DNA testing in screening for trisomies 21, 18 and 13: impact on the diagnosis of other chromosomal abnormalities. Fetal Diagn Ther 2014;35:174-184.

-9 Nicolaides KH: Turning the pyramid of prenatal care. Fetal Diagn Ther 2011;29:183-196.

$\checkmark 10$ Poon LC, Syngelaki A, Akolekar R, Lai J, Nicolaides KH: Combined screening for preeclampsia and small for gestational age at 1113 weeks. Fetal Diagn Ther 2013;33:16-27.

11 Greco E, Gupta R, Syngelaki A, Poon LC, Nicolaides KH: First-trimester screening for spontaneous preterm delivery with maternal characteristics and cervical length. Fetal Diagn Ther 2012;31:154-161.

-12 American College of Obstetricians and Gynecologists Committee on Genetics: Committee Opinion No. 545: Noninvasive prenatal testing for fetal aneuploidy. Obstet Gynecol 2012; 120:1532-1534.

13 Benn P, Borell A, Chiu R, Cuckle H, Dugoff L, Faas B, Gross S, Johnson J, Maymon R, Norton $\mathrm{M}$, Odibo A, Schielen P, Spencer K, Huang T, Wright D, Yaron Y: Position statement from the Aneuploidy Screening Committee on behalf of the Board of the International Society for Prenatal Diagnosis. Prenat Diagn 2013;33:622-629.
14 Devers PL, Cronister A, Ormond KE, Facio F, Brasington CK, Flodman P: Noninvasive prenatal testing/noninvasive prenatal diagnosis: the position of the National Society of Genetic Counselors. J Genet Couns 2013;22:291295.

15 Lo YM: Non-invasive prenatal testing using massively parallel sequencing of maternal plasma DNA: from molecular karyotyping to fetal whole-genome sequencing. Reprod Biomed Online 2013;27:593-598.

16 Fan HC, Blumenfeld YJ, Chitkara U, Hudgins L, Quake SR: Noninvasive diagnosis of fetal aneuploidy by shotgun sequencing DNA from maternal blood. Proc Natl Acad Sci USA 2008;105:266-271.

17 Chiu RW, Chan KC, Gao Y, Lau VY, Zheng W, Leung TY, Foo CH, Xie B, Tsui NB, Lun FM, Zee BC, Lau TK, Cantor CR, Lo YM: Noninvasive prenatal diagnosis of fetal chromosomal aneuploidy by massively parallel genomic sequencing of DNA in maternal plasma. Proc Natl Acad Sci USA 2008;105:2045820463.

18 Palomaki GE, Kloza EM, Lambert-Messerlian GM, Haddow JE, Neveux LM, Ehrich M, van den Boom D, Bombard AT, Deciu C, Grody WW, Nelson SF, Canick JA: DNA sequencing of maternal plasma to detect Down syndrome: an international clinical validation study. Genet Med 2011;13:913-920.

19 Bianchi DW, Platt LD, Goldberg JD, Abuhamad AZ, Sehnert AJ, Rava RP: Genome-wide fetal aneuploidy detection by maternal plasma DNA sequencing. Obstet Gynecol 2012; 119:890-901.

20 Sparks AB, Struble CA, Wang ET, Song K, Oliphant A: Noninvasive prenatal detection and selective analysis of cell-free DNA obtained from maternal blood: evaluation for trisomy 21 and trisomy 18. Am J Obstet Gynecol 2012;206:319.el-e9.

21 Ashoor G, Syngelaki A, Wagner M, Birdir C, Nicolaides KH: Chromosome-selective sequencing of maternal plasma cell-free DNA for first-trimester detection of trisomy 21 and trisomy 18. Am J Obstet Gynecol 2012;206: 322.e1-e5.

22 Norton ME, Brar H, Weiss J, Karimi A, Laurent LC, Caughey $\mathrm{AB}$, Rodriguez $\mathrm{MH}$, Williams J 3rd, Mitchell ME, Adair CD, Lee $\mathrm{H}$, Jacobsson B, Tomlinson MW, Oepkes D, Hollemon D, Sparks AB, Oliphant A, Song K: Non-invasive chromosomal evaluation (NICE) study: results of a multicenter prospective cohort study for detection of fetal trisomy 21 and trisomy 18. Am J Obstet Gynecol 2012;207:137.e1-e8.
23 Zimmermann B, Hill M, Gemelos G, Demko Z, Banjevic M, Baner J, Ryan A, Sigurjonsson S, Chopra N, Dodd M, Levy B, Rabinowitz M: Noninvasive prenatal aneuploidy testing of chromosomes 13, 18, 21, X, and Y using targeted sequencing of polymorphic loci. Prenat Diag 2012;32:1233-1241.

24 Nicolaides KH, Syngelaki A, Gil M, Atanasova $\mathrm{V}$, Markova D: Validation study of maternal blood cell-free DNA testing by targeted sequencing of single-nucleotide polymorphisms at chromosomes 13, 18, 21, X, and $\mathrm{Y}$. Prenat Diagn 2013;33:575-579.

-25 Nicolaides KH, Syngelaki A, Gil MM, Quezada MS, Zinevich Y: Prenatal detection of triploidy from cell-free DNA testing in maternal blood. Fetal Diagn Ther 2014;35:212-217.

26 Wang J, Pang GS, Chong SS, Lee CG: SNP web resources and their potential applications in personalized medicine. Curr Drug Metab 2012;13:978-990.

27 Chow KC, Chiu RW, Tsui NB, Ding C, Lau TK, Leung TN, Lo YM: Mass spectrometric detection of an SNP panel as an internal positive control for fetal DNA analysis in maternal plasma. Clin Chem 2007;53:141-142.

28 Gil MM, Quezada MS, Bregant B, Syngelaki A, Nicolaides KH: Cell-free DNA analysis for trisomy risk assessment in first-trimester twin pregnancies. Fetal Diagn Ther 2014;35:204211.

29 Struble CA, Syngelaki A, Oliphant A, Song K, Nicolaides KH: Fetal fraction estimate in twin pregnancies using directed cell-free DNA analysis. Fetal Diagn Ther 2014;35:199-203.

-30 Huang X, Zheng J, Chen M, Zhao Y, Zhang C, Liu L, Xie W, Shi S, Wei Y, Lei D, Xu C, Wu Q, Guo X, Shi X, Zhou Y, Liu Q, Gao Y, Jiang F, Zhang H, Su F, Ge H, Li X, Pan X, Chen S, Chen F, Fang Q, Jiang H, Lau TK, Wang W: Noninvasive prenatal testing of trisomies 21 and 18 by massively parallel sequencing of maternal plasma DNA in twin pregnancies. Prenat Diagn 2014;34:335-340.

- 31 Ashoor G, Poon L, Syngelaki A, Mosimann B, Nicolaides KH: Fetal fraction in maternal plasma cell-free DNA at 11-13 weeks' gestation: effect of maternal and fetal factors. Fetal Diagn Ther 2012;31:237-243.

32 Poon LC, Musci T, Song K, Syngelaki A, Nicolaides KH: Maternal plasma cell-free fetal and maternal DNA at 11-13 weeks' gestation: relation to fetal and maternal characteristics and pregnancy outcomes. Fetal Diagn Ther 2013;33:215-223.

33 Gil MM, Quezada MS, Bregant B, Ferraro M, Nicolaides KH: Implementation of maternal blood cell-free DNA testing in early screening for aneuploidies. Ultrasound Obstet Gynecol 2013;42:34-40

- 34 Nicolaides KH, Syngelaki A, Poon LC, Gil MM, Wright D: First-trimester contingent screening for trisomies 21,18 and 13 by biomarkers and maternal blood cell-free DNA testing. Fetal Diagn Ther 2014;35:185-192. 


\section{Errata}

In the article by Gratacós E and Nicolaides K, entitled 'Clinical perspective of cell-free DNA testing for fetal aneuploidies' [Fetal Diagn Ther 2014;35:151-155, DOI: $10.1159 / 000362940]$, in the section Implications of a Low-Risk Result, the 1,000 in the first sentence should be replaced with 100 ('The negative likelihood when cfDNA testing gives a low-risk result is about 100, 31 and 13 for trisomies 21,18 and 13, respectively [5].) and the 500,000 in the last sentence should be replaced with 5,000 ('For example, if prior screening by the combined test had shown that the risk for trisomy 21 was 1 in 500 and cfDNA testing gives a low-risk result, the chance that the fetus is affected is 1 in 5,$000 ; \ldots$;).

In the article by Gratacós E and Nicolaides K, entitled 'Clinical perspective of cell-free DNA testing for fetal aneuploidies' [Fetal Diagn Ther 2014;35:151-155, DOI: 10.1159/ 000362940], in the section Implications of a Low-Risk Result, the 1,000 in the first sentence should be replaced with 100 ('The negative likelihood when cfDNA testing gives a low-risk result is about 100, 31 and 13 for trisomies 21,18 and 13, respectively [5].') and the 500,000 in the last sentence should be replaced with 50,000 ('For example, if prior screening by the combined test had shown that the risk for trisomy 21 was 1 in 500 and cfDNA testing gives a low-risk result, the chance that the fetus is affected is 1 in 50,$000 ;. .$. ) and not as erroneously stated in a previous Erratum with 5,000 [Fetal Diagn Ther 2014;36:68]. 